\title{
INTERNATIONAL TRADE, INNOVATIONS AND TECHNOLOGICAL ACHIEVEMENT IN COUNTRIES
}

\author{
BURINSKIENE, A.
}

Abstract: This chapter examines the concept of innovations, also presents the models of innovations linked to international trade. Different types of models are analysed in the paper: models which present ,technology gap " between importing and exporting countries, models which introduce the impact of technological innovation on international trade, models which are dedicated to the change of trade costs and their impact to companies' decisions, also models which describe the company's contribution. Technological innovations are very important for international trade, at least as the part of infrastructure supporting international trade. Due to this the relationship between international trade and technological innovations is shortly analysed herein. The technology achievement index is introduced in the paper, also the achievement in e-commerce as advanced trade technology, is involved into empiric study. The results of the empiric study show that absolute technological leaders have huge capacity to apply advanced trade technology in recent decades.

Key words: innovations, technology, achievement, trade, models
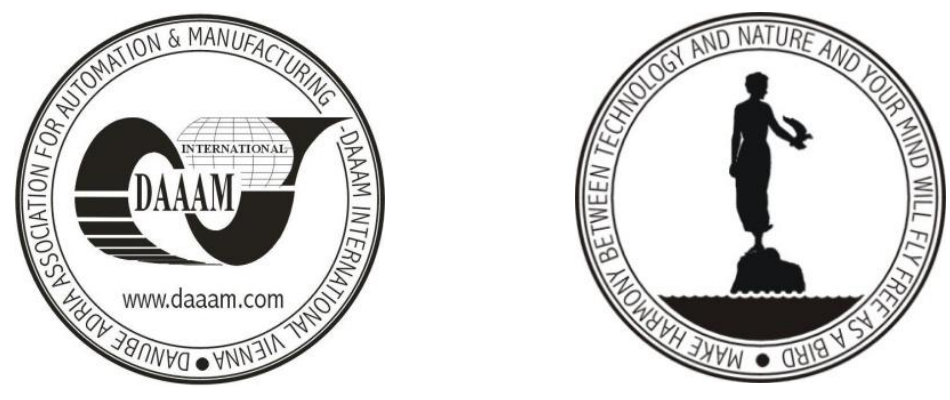

Authors' data: Dr.soc.sc. Burinskiene, A[urelija]; Vilnius Gediminas technical university, Faculty of Business Management, Sauletekio ave 11, LT - 10223, Vilnius, Lithuania, EU, aurelija.burinskiene@vgtu.lt

This Publication has to be referred as: Burinskiene, A[urelija] (2013) International Trade, Innovations, and Technological Achievement in Countries, Chapter 48 in DAAAM International Scientific Book 2013, pp. 795-812, B. Katalinic \& Z. Tekic (Eds.), Published by DAAAM International, ISBN 978-3-901509-94-0, ISSN 17269687, Vienna, Austria

DOI: $10.2507 /$ daaam.scibook.2013.48 


\section{Introduction}

International trade became increasingly important for studies in the post-war period. Without international trade, few nations could maintain the adequate standard of living. With only national resources being available, each country could be able to produce the limited number of goods. International trade allows the involvement of the enormous variety of resources and their worldwide accessibility. It also facilitates the distribution of the wide range of goods produced in different parts of the world.

Technological innovations are the engine of growth. Some population might argue that technology is driven only by science, which is largely independent of economic incentives. But the commercial exploitation of new scientific ideas (such as aircraft, machine tool, semiconductors, etc.) always requires investments. Only, when scientific idea has commercial value, it will be attractive for private companies. According some studies, companies invest in new technology when they have seen the opportunity to earn profit. The trade itself may help with technological dissemination, if foreign exporters suggest the ways to use technology and importers see how using new technology local products can become more attractive to consumers in their country.

Because of innovations higher capacity has to be introduced to support international trade. For example, air transportation carries an insignificant amount of freight $(0.2 \%$ of total tonnage) compared with maritime transportation but its importance is much more significant in terms of the total value $(15 \%$ of the value of global trade). Air transportation is the fastest and due to this about 70 times more valuable goods carried than with maritime transportation and about 30 times more than with land transport (in case of electronics).

The freight transport system composed of modes, infrastructures and terminals spans across the globe. It insures a physical accessibility to support international trade in terms of capacity, efficiency, and security. Due to innovations - improvements in the modes and infrastructures - higher capacity and throughput has been introduced. Ports are particularly important in such context that they are gateways to international trade through maritime shipping networks. Decreasing transport costs do more than increasing trade; they could also help change the location of economic activity.

Information technologies (ICT) have played a role by facilitating transactions for international business operations faster. This is particularly important since customer finalizes the financial transaction upon delivery; no need to wait several weeks due to the long distances involved.

These innovations basically changes products and services put on trade, the way (process) a given products are moving between countries and organisations, and replaces organisational routines with a new ones (behaviour). The growth can be achieved with horizontal innovations (increase in the number of varieties) and vertical innovation (the quality improvement of existing products).

Due to this, there is the growing number of empiric researches where authors seek to analyse relationship between innovations and international trade.

The study is organised as follows: in the first part of the study the concept of innovations is presented, later on the theoretical models mentioned in different theories are analysed, and finally the technology achievement's measure is introduced and the empiric study is shortly presented. In the first part of the study deeper 
understanding of innovations is provided. Herein different models (dynamic and static ones) are presented seeking to introduce technological change into the theory of world trade. These models cover open innovations, producer-centred and user-centred innovations, company-level innovations, horizontal and vertical innovations, etc. Also models, which are dedicated to the change of trade costs and their impact to companies' process and product innovation decisions, are reviewed.

Later on the technology achievement index (TAI) is introduced in the paper. Also the achievement in e-commerce as advanced trade technology is analysed in the empiric part of the study. Based on study results countries are ranked.

The study is based on historical method, comparative, and empirical analysis.

\section{The Concept of Innovations}

Innovation is a distributed process across many actors, companies and organizations, and is influenced by regulation, policy, and social pressure. Thinking widely, first, innovation is the part of a wider system; second, innovation has to be seen not only as product or process, but also interrelationship between these two has to be recognized - for example, incremental product and process improvement over the 16 years from 1880 to 1896 led to fall the price of light bulb around 80\%, and this ensured its wide spread among users; third, innovation, which fails to meet user needs, may not be accepted; fourth, production of products or services, which the market doesn't want, or designing processes, which don't meet the needs of end user, and will get resistance during diffusion. The better understanding of economic influences on innovation or vice versa is important in formulating public policy towards international trade (Park, 2010).

Talking about the way for each innovation, technology push and pull is considered. If technology eventually found its way to the marketplace (when we call this "technology push"), but if the market signalled needs for something new which then drew out new solutions to the problem and necessity becomes the mother of invention (when we call this "need pull"). Sometimes one of them ("pull" or "push") will dominate, but successful innovation requires the interaction between them both (Tidd, 2006).

Technological innovations are arguably the most powerful determinant of economic future. The improvement in the Western standard of living during the past would not have been possible without technical innovations.

Based on historical experience, it is hard to predict when big changes take place. But they involve the convergence of the number of trends, which results into a "paradigm shift" where the old order is replaced. For example, according "technoeconomic paradigm shift" the change impacts whole sectors or even whole societies.

Innovations take place within the set of rules which are and involve actors who adopt the innovation by doing what they do (talking about product, process, behaviour, etc.) but better (Tidd, 2006). Later on actors will continue with the new technology, which, first, may represent a different basis for delivering value e.g. telephone vs. telegraphy; second, may reduce benefits for old technology because the standard is just changed (when the combined effect has to be not underestimated); third, may involve completely new markets, which players have to see and not to ignore; fourth, new technology has to be picked up until it is not too late 
(technological leaders pick-ups product available in the market, other players have at best to be the fast followers).

The diffusion of innovations is unique. The diffusion for some innovations is faster, for others - slower. By analysing the diffusion of innovations in enterprises, the following types of enterprises may be distinguished (Fig. 1):

1) Technological leaders. They are among the first companies to introduce innovations and share common experiences with other enterprises;

2) Potential technological leaders. They face especially high costs for the introduction of technology;

3) Dynamic technological adopters. They devote more attention to the analysis of advantages and opportunities before adopting the innovation;

4) Technologically marginalised. This group consists of small enterprises that install innovations in the last stage.

In terms of percentage, the number of technological leaders is low; meanwhile the number of dynamic technological adopters - high.

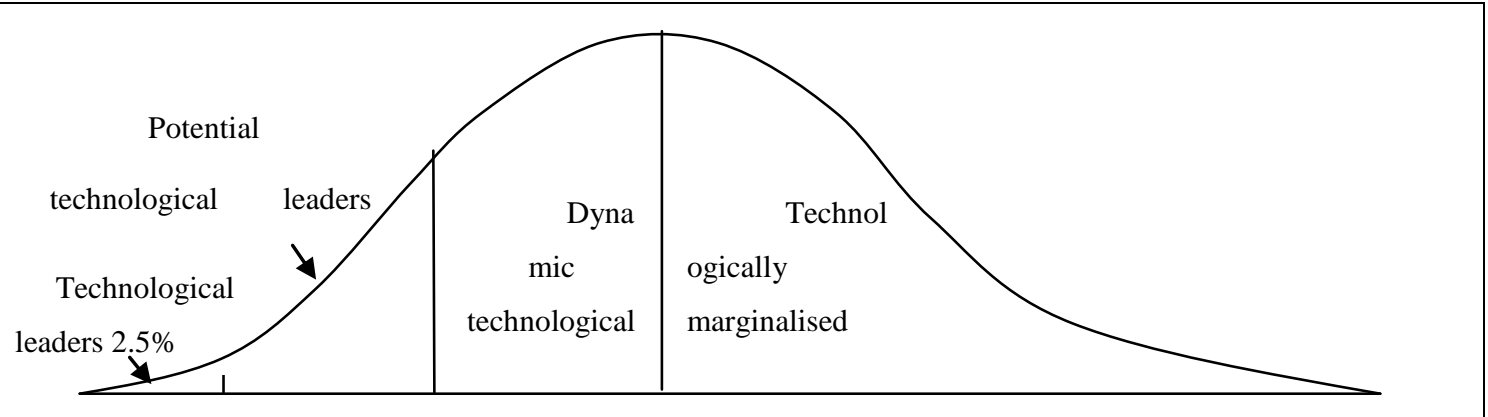

Fig. 1. The curve of the recognition of innovations according to Roger model (Sanchez, 2005)

The processes of the diffusion of innovations must be consistent. In order to achieve that innovation were recognized by the technologically marginalised companies, technologies are to be sometimes modified to facilitate their application to a major extent.

In different countries national advantages in natural resources help traditional industries to show technological advantage in new product fields. Resource-based theory of innovation assumes that company has access to various internal resources and competences to interact with environment in which they operate. The position of firm depends on its historical internal learning process, strategic future decisions, past successes, and failures. This suggests possible future directions for the company which include actual patterns of product innovation, organisational learning, financial investments, and technology achievement in country.

The international patterns of innovative activities have long recognized the important influence. International difference in prices can help generate very different pressures for innovation (e.g. the effects of different petrol prices on the design of automobiles in the USA and Europe); local natural resources may also create 
opportunities for innovation; also local private and public investment activities create innovative opportunities.

These days more companies carries innovative activities outside their home country (in the 1990s, only $12 \%$ of the innovative activities were carried outside home country by the world's largest 500 technologically active companies) (Tidd, 2006).

\section{The Models of Innovations}

Both the transfer of technologies to less developed countries and technological innovations in developed countries play an important role in determining changes of world trade over time. Small attention of theorists was attracted seeking to introduce technological change into the theory of world trade. Some explanations were given by Krugman (1994). He mentioned that existing models well suit for the analysis of technology one-for-all changes, but fewer suits to the analysis of on-going technical changes. For example, traditional models are oriented to the increase of efficiency in production for a given range of goods. Other - product cycle models investigate the development of new products.

The simplest model of innovations is presented by Grossman and Helpman (1991), which analyses the role of innovation on growth. The model assumes constant returns to scale. Under the assumption of increasing returns of capital when all other main features of the Grossman-Helpman model are unchanged, analysis shows that assumption of constant returns is "unrealistic" since innovation has "realistic" economic effects (Guarini, 2009).

The model of innovation, presented by Krugman (1994), involves the pattern of international trade, which is determined by the continuing process of innovation and technology transfer. Model is developed for innovating North and non-innovating (imitating) South. In North new products are introduced and produced immediately, but in South the technology is adopted with the lag. This lag gives the rise to international trade based on some interesting implications. Each product is exported when first introduced in North because of its monopoly position to South. After some time new goods become old goods and can be produced in both: North and South. There are also some assumptions in model: (1) Wages are higher in North because of monopoly position, even if labour productivity is the same in both regions; (2) Living standards are higher in North; (3) North exports new products and imports old products, when wage difference between North and South is significant.

The technology transfer from North to South will have negative effect in North (temporary reduction in northern welfare). If north extending the range of new goods, the demand of products (produced in North) increases. The any given relative price rises and workers' real wage in terms of output rises as well. Since developed North countries constantly innovate, new industries are emerging there. In case of capital reallocation from North to South, the relative income of South workers rises. But if the relative price of northern product rises, capital moves back (from South to North). This presents the continuing process of innovation and technology transfer.

Further it is interesting to know the effect technology transfer has. The change of the number of products produced and the change of production location have effect on world productivity. This effect shows that innovation through the increase of the 
range of goods influence the increase of real world productivity. It also affects the distribution between South and North regions (Korner, 2011).

Zon et al. (1997) transform the Krugman model in three ways. First, it is interpreted that in North there are the high-tech sectors, which produces new variety of goods. These goods can be produced using high-skilled workers only. When in South produce low-tech variety of goods using low-skilled workers. Second, lowskilled workers (which aren't mobile) can be replaced with high-skilled workers (which are mobile within economy) and they can produce low-tech goods. Third, the rate of imitation depends on the behaviour of entrepreneurs who switches from hightech to low-tech production technology.

Northern firms develop new final-goods varieties and products in North, and plans cost-reduction over their infinite life-times in South. Some countries, often through the activities of MNEs, have become active (such as S. Korea, Taiwan) in horizontal innovation (increase in the number of varieties) and others (such as China, India) in vertical innovation (quality improvement of existing products). They are even classified into horizontal innovations of final and intermediate goods, and vertical innovations of final and intermediate goods. Consumers benefit from accelerated vertical innovation but may lose from accelerated horizontal innovation.

The factors which make a country to become receptive to the technology embodied in foreign goods are closely linked, among others, to the degree of openness to import in the country, what means its trade and financial liberalisation, as well adequate institutional settings. Hence, the more a country is able to absorb foreign knowledge and improve upon technologies conceived in other countries, the more it will gain competitiveness, and the more it will benefit in terms of its long-run growth rate of income (Cavallaro \& Mulino, 2007).

The "technology gap" model of international trade. A simple model developed to present the relationship between technology and trade. Basically it is Ricardian model which implies the characteristics of countries and products: countries are ranked by the level of technology and products are ranked by "technology intensity". Then each country gets a niche on the scale of products which is appropriate to its position as technology leader (Krugman, 1994). The effect of technological progress is analysed in both cases: progress in advanced country that widens "technology gap" between it and another country, and progress in a less advanced country that narrows the "technology gap". In the first case, the technological progress of leader opens up greater opportunity to international trade. Technical advance means the rise of export for the advanced country and gains from progress abroad for the less advanced country; real incomes in both countries rise. In second case, the "catch-up" step by follower tends to hurt the leader by eliminating the gains from international trade.

Authors focus on vertical innovations and derive the impact of "catch-up" process on import and export demand functions. The way for lagging-behind country to become competitive in international markets depends on its ability to "catch-up" technologically with more advanced countries. This ability is more important rather than trade gains from progress abroad.

It is stated in theory that there are various channels through which technology can be transmitted across countries. One channel is related with the diffusion of technology. Technology is embodied in capital and intermediate goods so the direct import of these goods is one channel of transmission. These countries, which have 
faster growth in TFP, import more from the world's technology leaders. One note about EU new states members to be added. The new members are very different from the old ones. The new member regions are catching up technology standards of Western Europe, they are dynamic with fast rising incomes (Baldwin \& Wyplosz, 2009).

Cavallaro \& Mulino (2007) built model where technology "catch-up" process is driven by international knowledge spill overs and facilitated by the integration of markets.

A gravity model. A model that has been widely used to study the determinants of trade is the gravity model. The gravity model is augmented by authors MartinezZarzoso \& Marquez-Ramos (2005). Herein variables are used to analyse the impact of technological innovations and transport infrastructure on international trade. Authors have analysed the relationship between trade, technological innovation and geography. Seeking to analyse how technological innovation transforms the geography of trade, they tested empirically how the innovation and geographical factors influence international trade. Martinez-Zarzoso \& Marquez-Ramos (2005) study results support the hypothesis that countries tend to trade more when they are "closer" from a technological point of view. Authors also analysed if technology has any effect on geographical distance in a more globalised and integrated world. Study results showed that the development of information technology has lowered the effect of geography on trade, e.g. distance on trade; this means that the development of technological innovation means that long distances are less important nowadays than in the past.

Marquez-Ramos \& Martinez-Zarzoso (2010) studied the relationship between technological innovation and international trade (in particular, the effect of technological achievement on exports). Authors analysed the effect of technological variables on sectorial exports. They investigated also the existence of possible nonlinear relationship, since the effect of improved technological innovation on trade could be different in countries (it depends on technological achievement). Study findings showed that non-linear relationship exists as the expected; positive effect of technological innovation on export performance is confirmed. "U-shaped" relationship is found between export and the creation of technology; also between export and the diffusion level of old innovations. Positive effect of technological innovation on exports received for the countries which classified as technological leaders (according TAI) and potential leaders. An inverted-"U-shaped" relationship is found between export and the diffusion of recent innovations; also between exports and human skills. Therefore, the low and high level of these components leads to lower exports, whereas an intermediate achievement leads to higher exports.

Overall, the creation of technology, according Marquez-Ramos \& MartinezZarzoso (2010), fosters international trade in all countries; the TAI shows only the size of the effect. Of course, the contribution of single country to export varies, e.g. countries with the intermediate diffusion of old innovations export the less.

Some models are dedicated to the diffusion. These are demand side models and supply side models. Demand side models focus on demand side of the diffusion process, and ignore supply side factors. While, supply side models emphasize the relative advantage of an innovation, the availability of information, the reduction of barriers to use, and feedback between developers and users. 
The Probit model takes the population of potential leaders and adopters. It assumes that potential leaders and adopters have different threshold values for costs or benefits, and will only adopt beyond some critical or threshold value. In such cases differences in threshold values are used to explain different level of adoption. This suggests that higher number of similar potential leaders and adopters helps to have faster diffusion. In the Probit model potential leaders and adopters know the value of adoption, but delay adoption until the benefits are sufficient. However, it is unrealistic to assume that they have perfect knowledge about the value of innovation.

Therefore, Bayesian models of diffusion allow potential leaders and adopters to hold different beliefs regarding the value of the innovation, which they may revise according to the results of trial tests of the innovation. Because these trials are private, imitation can't take place till other potential companies can't learn from the trials. This suggests the idea that better informed potential leaders and adopters may not necessarily adopt innovation earlier than the less well informed once, which was the assumption of earlier diffusion models.

The simple epidemic model - the model that was the earliest created and still often is used. It assumes that the spread of innovations depends on geographical proximity of existing and potential leaders and adapters. This model highlights the communication and the provision of clear technical and economic information. However, the epidemic model has been criticized because it assumes that all potential leaders and adapters are similar or have the same needs. Due to this, the Bass model of diffusion was modified seeking to include two different groups of potential adapters: innovators, who are not subject to social emulation and subsequent imitators, they are not innovating themselves. The presented Bass model is still highly used in economics.

The choice between the last two models depends on the characteristics of innovation and the nature of potential leaders and adapters. The simple epidemic model provides a good fit to the diffusion of new processes, techniques and procedures; whereas the Bass model well fits for the diffusion of consumer products. However, the mathematical structure of the epidemic and Bass models tends to overstate the importance of differences in adapter characteristics, but tends to underestimate the effect of macroeconomic and supply side factors. In general, both of these models are dedicated for diffusion, but they are used when the total potential market is known, this means that they are more oriented to the modifications of existing products and services, rather than for totally new innovations.

The dynamic models of innovation. Innovation is reflected to the variety and quality of either final goods or intermediate inputs. Findlay (1978) developed dynamic model, which includes technology transfer between high-technology country and low-technology country. The model is based on single idea that new technologies are diffusing, because old machines are anyway depreciating. Authors mention that technology and trade are interlinked.

Looking at process and products innovations the AU model describes the patterns associated with their life cycles. Model comes with an empirical observation that the development of product and process vary not only with each other but also over the time. At the beginning of new product life cycle, product innovation occurs and is driven in part by the active participation of leading end users. This product's improvement is delivered very rapidly, but over the time still requires some learning 
from innovating company. There are three phases. The period of rapid innovation is called "fluid" phase. As product innovation slows down, process innovation accelerates and reaches peak in next phase, which is called "transitional" phase. This phase starts with the rapid rise of product demand. Market competition between companies requires product's improvement in quality and reduction in price. During this phase the industry becomes concentrated but producing companies don't reach profit and start struggle to get the advantage of economies of scale. During the last phase, which is called "specific" phase, processes becomes capital intensive and neither product nor process can be easily changed due to their interdependence. Innovations become ever more incremental. In such environment changes are more difficult; industries are vulnerable to breakthroughs that reset the cycle.

The evolution of more realistic dynamic models of innovation is still on-going. Formal dynamic models of technological innovation are relatively underdeveloped; and existing models are typically quite aggregate and don't separate product from process innovation. There is a clear need for the dynamic models, which reflect company-level and industry-level causal factors and to provide other insights.

They have to be dedicated for the complex systems of disruptive and discontinuous events that involve different networks of actors and sources.

Open innovations and models. Economic history also holds the examples of open innovation. A system under which innovation is non-proprietary and occurs under free and open development conditions (it is an alternative or complement to proprietary innovation). In most open innovation settings, goods or inputs are actually available for free. Chesbrough (2003) argues that open innovations may be a more profitable than closed innovations at some time. He provides the number of case studies, where companies like Merck, Xerox, Intel, IBM, and Proctor \& Gamble, etc. found that given open access to their technologies helped to create opportunities for further innovation and commercialization and to achieve increase in overall value of their technologies. Let's start theoretical analysis from the Saint-Paul (2003) model. Here the technology for creating it is available for free (in the public domain); no licensing or royalty fees are associated with it. Supplier then charges only the marginal costs associated with manufacturing the good. One especially useful feature of Saint-Paul (2003) model is that the model incorporates both closed and open innovations. Other theoretical models that focus on only one type of innovation miss out on the joint interactions; for example, open source communities may generate proprietary innovation, when the overall technical change is ambiguous. According Harhoff et al. (2003) theoretical model, the chance that innovation will be widely adopted increases when other factors are held as constant (Park, 2010).

Models, which include producer-centred and user-centred innovations. The growing number of researches focuses on these both models. Empirical studies have found that many successful products, which were promoted to goods market by producers (such as sports equipment, scientific instruments, medical applications, and ICT), were actually developed by users. In addition, innovating users often were not taking the advantage of available intellectual property protections or innovation subsidies.

Evidence has been rapidly growing towards users, which rather than producers, usually create and modify goods to serve their own needs. Users can be either companies or individuals that expect to benefit from using an innovative technology. 
In contrast, producers expect to benefit from selling it. Producers and end users can have different relationships to different innovations. For example, Boeing is the producer of airplanes and the user of machine tools. In such case, Boeing is a producer and end user (innovator) (Hippel \& Jong, 2010; Hippel, 2005).

Models, which include company-level innovation. These models generate insights into the nature of innovation and decision making requirements at the level of company, pointing important links between innovation process and other the most important processes.

These models cover the introduction of new or improved product, process or service to the companies. Since the 1950s till 1990s there are five generations of these models. The first decade was characterised by successive waves of technological innovations. R\&D push is highlighted in these models. The second decade stands out for market pull. The market is full of ideas and provides direction to research and development (R\&D) activities. The third decade involves push or pull-push combinations. During fourth decade the integration between R\&D and production is emphasized. Last decade involves customers-centred innovations and attention to corporate flexibility and speed of development (time-based development). Increased focus on quality and other non-price factors. This decade is famous because of the development supported by advanced information technology (Hobday, 2005).

Schmidt-Tiedemann (1982) concomitance model divides innovation into three spheres: exploration, innovation and diffusion. The term of concomitance is used to show how different business functions (R\&D, sales, and distribution, etc.) accompany and interact with each other during innovation process.

Abernathy and Clark developed model describing such phases: initial, continuous, and fluid phases during which two dimensions are considered:

1) the target (what will be new technology and for whom it will be dedicated),

2) the technical - how technology will be created and delivered (Tidd, 2006).

The Wheelright and Clark (1992) funnel model shows how ideas are selected and how innovation portfolio could be managed. The model incorporates feedbacks from one stage to another during phases are such as: idea generation, overall design of product, and rapid focused development.

Waterfall and spiral software development models are also widely known and provide guidelines how to manage process through software life cycle.

Utterback and Abernathy model highlights the changing character of relationship between product and process innovations when company grows, volume increases, market matures, and industry structure evolves. This model involves industry standard to product innovation in early stage, and later paves the way to process-centred innovation when volume grows (Bresson \& Townsend, 1981). Changes from unit production to mass production and to continuous process are very important, when the relationship between product and process innovations is considered. For example, process intensive phase is never reached and product design stage is not touched at process level. Also high costs are the attribute of unit 
production. Moving from unit production to mass production learning has significant role (Hobday, 2005).

Linear stage model describes how companies (maybe entire industries) are moving from one stage to another: from $R \& D$ activity to production, or from early to late stage if product life-cycle is considered.

Naive stage model has the view to innovation as one discrete activity followed by another isolated activity (each activity or stage are isolated); the feedback loop between stages is not taken into account in such model.

Atkeson \& Burstein (2010) build the model used to measure the impact of international trade on firms' product and process innovations' decisions. The reduction in international trade costs can have a substantial impact on individual company's decisions to exit, export, and invest in R\&D activities seeking to improve the costs or quality of existing products and create new ones. There are two effects included into model: the first is the direct effect, which is due to the change of trade' costs and their impact to innovation's decisions; the second is indirect effect that arises from the changes in companies' decisions (towards process and product innovations) caused by the change in trade costs.

The reduction in trade costs leads to the re-allocation of production; and investments from smaller, less-productive, non-exporting companies are re-allocated to larger, more-productive, exporting companies. This re-allocation does lead to a change in the productivity of the average company; also the productivity differences across companies that result into larger increase in the volume of international trade (Atkeson \& Burstein, 2010). Melitz (2003) model (involving Pareto productivity) show that the welfare gains from international trade only depend on the level of trade, which was before and after the change in trade costs, also on the gravity-based elasticity of trade describing the changes in trade costs, and that's it (i.e. other variables of the model shouldn't be taken into account).

Atkeson \& Burstein (2010) analytically study the impact of change in marginal trade's costs through three special cases. In the first case, it is assumed that all companies export. In the second special case, only the most productive companies export; they are able to choose exit, export, and take process innovation's decisions. Main results correspond to the model of Melitz (2003). In the third case, companies have endogenous productivity dynamics which rises with the application of process innovation, but their exit and export's decisions are independent from company's size. In the second and third mentioned cases, it is also assumed that the real interest rate is zero. Results showed that changes in trade costs have the same impact on steady-state productivity, in all mentioned three cases.

The extent of companies' export is important and influences the changes of trade costs. In Atkeson \& Burstein (2010) model it is shown that, in response to a decline in international trade costs, changes in process and product innovations largely offset. Authors also find that the dynamic welfare gains from trade, when process innovation is elastic, are not substantially larger than those gains when it is not. This is true despite the fact that elastic process innovation leads to very large dynamic responses of exports and the increase in firm's size.

Empirical researches show that bigger adjustments in distribution occur due to the entries or exits decisions of companies in market. Also results shows that open economy leads to new gains when scale economies is reached on branch-level 
(Tybout, 1991). Foreign competition forces branches, which are below the efficient scale, to exit; foreign competition improves the usage of new technologies (the increase of technology's acceptance is seen between industries). Some studies have included also the maturity of branch before the choice of technology but still very little has been done. Some researches show that multinational enterprises (MNEs) buy foreign counterpart seeking to distribute technology faster than domestic ones (Hallak, 2000).

Authors Navas-Ruiz \& Sala (2007) added into their model the possibility for companies to adopt more costly productive technologies and showed that the productivity of manufacturing branch increases in response to lower trade costs. When scale of operations increases exporters get returns from costly productivityrelated investments, since trade entails a larger access to product markets. The demand to company's product increases the production capacity of domestic exporters. In addition this suggests that exporters have to adapt more innovative technologies (Navas-Ruiz \& Sala, 2007).

Finally, it is evident the main assumption typical for all presented theoretical models - once created innovations are diffused and adopted immediately and easily. However, in practice, innovations may sit on the shelf for some time or could have faced some difficulties during adoption. It would be useful for authors during theoretical discussions to use the term „successful innovations“ or „successful introduction" talking about new or improved product, process or service.

\section{Technological Achievement in Countries: Empiric Study}

Technological innovation can be defined as the countries' capacity to put new ideas into practice by developing new goods, services, and processes, which play the key role in international trade and economic development (Marquez-Ramos et al., 2010).

The United Nations Development Programme (UNDP) presents the technology achievement index (TAI), which is used to measure how well each country is creating and diffusing technology and building a human skill base, reflecting capacity used for the technological innovations. It is the composite measure of technological progress that ranks countries on a comparative global scale.

The TAI is calculated from four indicators: (1) the creation of technology, (2) the diffusion of recent technologies, (3) diffusion of old technologies, and (4) human skills:

1) The indicators for creation of technology are patents granted per capital unit and royalty and license fees received from abroad per capital unit.

2) The diffusion of recent technologies is calculated from the number of Internet hosts per capital unit and the share of high-technology \& medium-technology exports as the percentage of all exports.

3) Indicator for the diffusion of old technology is telephones (land line and cellular) per capital unit and electricity consumption per capital unit. 
4) Indicator of human skills is calculated based on the average number of years of schooling and the gross enrolment ratio at the tertiary level in science, mathematics, and engineering.

Many elements can be used to present technological achievement in country, but a composite assessment is more easily made based on a single composite measure than big range of different measures.

The index is calculated as the simple average of these four indicators. The indicators in each dimension are given equal weight, and the dimensions are given equal (one-quarter) weight in the final index. This means that the diffusion of technology is given more weight since two of the four indicators deal with this.

The TAI is presented for 68 countries. For other countries, data were missing or unsatisfactory for one or more indicators, so the TAI is not measured (as it could not be estimated).

The countries are classified in four blocks as shown by the existence of a gap between the last country in one group and the first country in the next group (according Martínez-Zarzoso \& Marquez-Ramos, 2005; Archibugi \& Coco, 2002).

First group consists of Technological leaders (TAI is above 0.5). This group includes countries with a high capability to create and sustain technological innovations.

Second group - Potential Technological Leaders (TAI is from 0.35 to 0.49 ). Group includes countries that have invested in all four dimensions (creation of technology, diffusion of recent innovations, diffusion of old innovations and human skills. Scores are derived as an index relative to the maximum and minimum achieved by countries in any indicator of above mentioned dimensions), but have been less innovative.

Third group - Dynamic Technological Adopters (TAI is from 0.19 to 0.34 ). Countries in this group try to achieve growth from the adoption of technology and in their level of development (Table 1).

Fourth group - Technologically Marginalised (TAI is below 0.19). The last group consists of marginalised countries: many African countries belong to this group. It is difficult for them to gain access even to the oldest technologies; so low technological achievement level is associated to low income levels (UNESCO, 2010).

All countries need to have the capacity because the ability to apply technology can't be fully done without the capacity allowing adapting products and processes to local conditions (Desai et al., 2002). All mentioned factors: the availability of human capital, the structure and flexibility of trade and financial institutions, the degree country's openness to foreign trade impact the TAI in specific country.

As the TAI is also incomplete and technological achievements are more complex in countries, it is impossible to reflect the full range of technologies - from manufacturing to transport to trade technologies.

In addition, the achievement in advanced trade technology is involved into study; particularly the achievement in e-commerce technology is measured by author. E-commerce is quite new technology. It provides more opportunities to conduct transactions and encourage the development of new forms of trade. E-commerce can 
be described as the usage of electronic networks (Internet and electronic data interchange (EDI) networks) for buying and selling goods. In literature quite often the broader term is used. E-commerce is considered as a concept for trade based upon products and services that are being marketed, contracted, and paid for over the Internet (Bergendahl, 2005). E-commerce is considered, as employment of electronic networks for simplifying and expediting the purchase-sales process of goods (Sarapovas, 2005). This means also that the usage of e-commerce technologies is the main factor, determining the perspectives of international trade development.

\begin{tabular}{|c|c|c|c|c|c|c|c|c|c|c|c|}
\hline \multicolumn{3}{|c|}{ Leaders } & \multicolumn{3}{|c|}{ Potential Leaders } & \multicolumn{3}{|c|}{ Dynamic adopters } & \multicolumn{3}{|c|}{ Marginalised } \\
\hline Rank & Country & TAI & Rank & Country & TAl & Rank & Country & TAl & Rank & Country & TAl \\
\hline 1 & Finland & 0.74 & 18 & Spain & 0.48 & 34 & Uruguay & 0.34 & 60 & Nicaragua & 0.19 \\
\hline 2 & USA & 0.73 & 19 & Italy & 0.47 & 35 & Thailand & 0.34 & 61 & Pakistan & 0.17 \\
\hline 3 & Sweden & 0.7 & 20 & Czech Rep. & 0.47 & 36 & S. Africa & 0.34 & 62 & Senegal & 0.16 \\
\hline 4 & Japan & 0.7 & 21 & Slovenia & 0.46 & 37 & \begin{tabular}{|l|} 
Trinidad \& \\
Tobago
\end{tabular} & 0.33 & 63 & Ghana & 0.14 \\
\hline 5 & S. Korea & 0.67 & 22 & Hungary & 0.46 & 38 & Panama & 0.32 & 64 & Kenya & 0.13 \\
\hline 6 & Holland & 0.63 & 23 & Slovakia & 0.45 & 39 & Brasil & 0.31 & 65 & Tanzania & 0.08 \\
\hline 7 & UK & 0.61 & 24 & Greece & 0.44 & 40 & Phillipines & 0.3 & 66 & Nepal & 0.08 \\
\hline 8 & Canada & 0.59 & 25 & Portugal & 0.42 & 41 & China & 0.3 & 67 & Sudan & 0.07 \\
\hline 9 & Australia & 0.59 & 26 & Poland & 0.41 & 42 & Bolivia & 0.28 & 68 & $\begin{array}{l}\text { Mozambi- } \\
\text { que }\end{array}$ & 0.07 \\
\hline 10 & Norway & 0.58 & 27 & Bulgaria & 0.41 & 43 & Peru & 0.27 & \multicolumn{2}{|c|}{ World Average } & 0.4 \\
\hline 11 & Germany & 0.58 & 28 & Malaysia & 0.4 & 44 & Columbia & 0.27 & & & \\
\hline 12 & Ireland & 0.57 & 29 & Mexico & 0.39 & 45 & Tunisia & 0.26 & & & \\
\hline 13 & N. Zealand & 0.55 & 30 & Croatia & 0.39 & 46 & Jamaica & 0.26 & & & \\
\hline 14 & Belgium & 0.55 & 31 & Romania & 0.37 & 47 & Iran & 0.26 & & & \\
\hline 15 & France & 0.54 & 32 & Costa Rica & 0.36 & 48 & Praguay & 0.25 & & & \\
\hline 16 & Austria & 0.54 & 33 & Chile & 0.36 & 49 & El Salvador & 0.25 & & & \\
\hline \multirow[t]{10}{*}{17} & Israel & 0.51 & & & & 50 & Ecuador & 0.25 & & & \\
\hline & & & & & & 51 & Syria & 0.24 & & & \\
\hline & & & & & & 52 & Egypt & 0.24 & & & \\
\hline & & & & & & 53 & Dominica & 0.24 & & & \\
\hline & & & & & & 54 & Zimbabwe & 0.22 & & & \\
\hline & & & & & & 55 & Algeria & 0.22 & & & \\
\hline & & & & & & 56 & Indonesia & 0.21 & & & \\
\hline & & & & & & 57 & Hondurus & 0.21 & & & \\
\hline & & & & & & 58 & Sri Lanka & 0.2 & & & \\
\hline & & & & & & 59 & India & 0.2 & & & \\
\hline
\end{tabular}

Tab. 1. The Technology Achievement Index (TAI). Source: UNESCO (2010)

During research the achievements on e-commerce technology are examined for 2599 multinational enterprises (MNEs) from trade industry of 157 foreign countries. In general, results show that MNEs are more advanced than national enterprises. Results showed that e-commerce technologies are applied in 65 countries (from 157 world countries). The average rate is $18 \%$ for selected countries.

In order to avoid test errors, the application practices of e-commerce technologies are presented only for those countries where the number of trade enterprises, which are included in Planet Retail (2008) database, is significant. For this research non-random sampling is used. The sample size is determined by using on-line calculation. The results were showed that confidence interval is equal to $3.14 \%$.

Based on results, countries are selected accordingly: 
Technological Leaders (when the application of e-commerce technology between MNEs is above 23\%). Top three Technological Leaders are Sweden (rate is $33 \%)$, UK (33\%), and Japan (29\%).

Potential Technological Leaders (the application of e-commerce technologies between MNEs is from $12 \%$ to $22 \%$ ). Most of the countries, which apply ecommerce technologies, fall under this group.

Dynamic Technological Adopters (when the application of e-commerce technologies between MNEs is less than 11\%).

Technologically Marginalised (the e-commerce technologies are not applicable by MNEs in the country). 92 countries fall under this group.

Finally, TAI results were compared with achievements on e-commerce technology in different countries. The comparison of both: TAI and the application of e-commerce technologies is conducted to reveal how TAI represents the application of e-commerce technology in countries; also to classify countries into groups representing difference in technological achievement.

In the literature these main methods, which can be used for the classification of countries, are presented:

1) estimation methods. The criteria used for estimation vary and may include the TAI growth, size, etc. Countries could be evaluated on the basis of several criteria; later the markets with similar scores are grouped. These methods are used when is impossible to give an accurate picture using only statistical evidence.

2) historical methods. Different political, economic, technological, and social indicators are used with their historical values seeking to identify and group countries, which have different achievements' levels.

Based on historical method it was noted that the application of e-commerce technologies differs in various countries.

Finally, the achievements in e-commerce are compared with TAI for 34 countries and these countries are classified into such 6 groups:

1) Absolute Technological Leaders: Finland, Sweden, Japan, United Kingdom, Norway, France;

2) Technological Leaders in TAI but Potential Technological Leaders in ecommerce: USA, Netherlands, Canada, Germany, Ireland, Belgium, New Zealand, Austria;

3) Absolute Potential Technological Leaders: Spain, Italy, Czech Republic, Slovakia, Greece, Portugal, Poland, Mexico, Slovenia;

4) Dynamic Technological Adopters in TAI and Potential Technological Leaders in e-commerce: Brazil, India, Columbia, Tunisia;

5) Potential Technological Leaders in TAI but Dynamic Technological Adopters in e-commerce: Hungary, Malaysia;

6) Absolute Dynamic Technological Adopters: Thailand, El Salvador. 
The results of empiric study show that some countries are ranked higher according TAI and lower in the application of e-commerce technology or vice versa. In absolute cases it's evident that technological achievement is stable in the country. Absolute technological leaders have huge capacity allowing the application of technology in recent decades.

There are some countries that have successfully used technology for sustained economic growth and for equitable development. The results show the high levels of commitment to the diffusion of technology usually through the population and the development of human skills. Second, countries, which adopted very pro-active policies and provided many incentives for businesses to train their workers, have invested lots of money into the diffusion of technology. Third, there are countries where diffusion of technology has not been widespread, and capacity has not been translated into to any significant level (such cases could be met for large country with very large population). This shows that country dilutes its strengths for technological achievement. Finally, the technical advances raise the export for the advanced country and gains from progress abroad for the less advanced country.

\section{Conclusion}

Overall, the creation of technology fosters international trade in all countries, independently form their technological achievements. Of course, the contribution of single country to export varies, e.g. countries, which have higher diffusion of new innovations, export more and countries, which have higher diffusion of old innovations, export less. Looking from this perspective the better understanding of these effects is important in formulating public policy towards international trade.

However, some innovations are incremental, which diffusion can lead to large gains in international trade.

Talking about countries, there are some countries that have successfully used technology for sustained economic growth and for equitable development show the high levels of commitment to the diffusion of technology usually through the population and the development of human skills. Second, there are countries, which adopted very pro-active policies and provided many incentives for businesses to train their workers, have invested lots of money into the diffusion of technology. Third, there are countries where diffusion of technology has not been widespread, and capacity has not been translated into to any significant level (such cases could be met for large country with very large population). This shows that country dilutes its strengths for technological achievement.

The results of empiric study helped to rank countries into six groups. Some countries are ranked higher according TAI and lower according the application of ecommerce technology or vice versa. In absolute cases it's evident that technological achievement is stable in advanced country. Absolute technological leaders have huge capacity allowing applying technology in recent decades. The technical advances raise the export for the advanced country and gains from progress abroad for the less advanced country. 
In general, presented models dedicated for diffusion, are used when the total potential market is known, this means that they are more oriented to the modifications of existing products and services, rather than for totally new innovations. Finally, it is evident the main assumption typical for presented theoretical models - once created innovations are diffused and adopted immediately and easily. However, in practice, innovations may sit on the shelf for some time or could have faced some difficulties during adoption. It would be useful for authors during theoretical discussions to use the term „successful innovations“ or „,successful introduction" talking about new or improved product, process or service.

The evolution of more advanced dynamic models is still on-going. Formal dynamic models are relatively underdeveloped; and existing models are typically quite aggregate and don't separate product from process innovations. There is the clear need for the dynamic model to reflect company-level and industry-level causal factors, and to provide more insights.

The research is limited and not covers the costs and benefits of innovations of different stakeholders. As it is the complex systems of disruptive and discontinuous events that involve different networks of actors and sources, for the next step the incentives and constraints that exist at the level of the company, economy and international trade have to be considered. So, this is the objective for further research.

\section{References}

Archibugi, D. \& Coco, A (2002). A new indicator of technological capabilities for developed and developing countries. World Development, Vol. 32, No. 4, 629-654, ISSN: 0305-750X

Atkeson, A. \& Burstein, A. T. (2010). Innovation, Firm Dynamics, and International Trade. Journal of Political Economy, Vol. 118, No. 3, 433-484, ISSN: 0022-3808

Baldwin, R. E. \& Wyplosz, C. (2009). The Economics of European integration. McGraw-Hill Education, 12-25, UK

Bergendahl, G. 2005. Models for investment in electronic commerce - financial perspectives with empirical evidence. Omega, Vol. 33, 363-376, ISSN 03050483

Bresson, C. \& Townsend, J. (1981). Multivariate models for innovation-looking at the Abernathy-Utterback model with other data. Omega, Vol. 9, 429-436, ISSN 03050483

Cavallaro, E. \& Mulino, M. (2007). Vertical innovation and catching up: implications for trade and growth, CIDEI Working Paper, 1-24, Italy

Chesbrough, H. (2003). Open Innovation: The New Imperative for Creating and Profiting from Technology, Harvard Business School Press, 27-39, Cambridge

Desai, M.; Fukuda-Parr, S.; Johansson, C. \& Sagasti, F. (2002). Measuring the Technology Achievement of Nations and the Capacity to Participate in the Network Age. Journal of Human Development, Vol. 3, No. 1, ISSN 1464-9888

Findlay, R. (1978). Relative backwardness, direct foreign investment, and the transfer of technology: a simple dynamic model. The Quarterly Journal of Economics, Vol. 1, No. 92, 1-16, ISSN 1531-4650

Grossman, G. M. \& Helpman E. (2007). Endogenous Innovation in the Theory of Growth. Journal of Economic Perspectives, Vol. 8, No. 1, 23-44, ISSN 0895-3309 
Guarini, G. (2009). Innovation and growth in the Grossman-Helpman's model with increasing returns: a note, MPRA Paper, 1-12, Roma

Hallak, J. C. (2000). Domestic firms vs. multinationals: the effects of integration, Harvard University Press, 9-27, Harvard

Harhoff, D.; Henkel, J. \& Von Hippel, E. (2003). Profiting from Voluntary Information Spillovers: How Users Benefit by Freely Revealing their Innovations. Research Policy, Vol. 32, 1753-1769, ISSN: 0048-7333

Hippel, E. \& Jong, J. P. J. (2010). Open, distributed and user-centered: towards a paradigm shift in innovation policy, EIM Research reports, 31-45, Zoetermeer Hippel, E. (2005). Democratizing Innovation, MIT Press, 20-43, Cambridge Hobday, M. (2005). Firm-level Innovation Models: Perspectives on Research in Developed and Developing Countries. Technology Analysis \& Strategic Management, Vol. 17, No. 2, 121-146, ISSN 0953-7325

Korner, J. (2011). International Trade - Multinational Corporations and Technology Transfer, Verlag, 3-21, UK

Krugman, P. R. (1994). Rethinking international trade, MIT Press, 24-96, Cambridge Martínez-Zarzoso, I. \& Marquez-Ramos, L. (2005). International trade, technological innovation and income: gravity model approach, WP-EC, 1-31, Spain Marquez-Ramos, L. \& Martinez-Zarzoso, I. (2010). The Effect of Technological Innovation on International Trade: A Nonlinear Approach. Economics: The OpenAccess, Vol. 4, No. 11, 1-33, ISSN: 18646042

Park, W. G. (2010). Innovation and economic dynamics, Idea Connect Ltd, 1-34, USA

Planet Retail (2008). Database, Available from: http://www.planetretail.net, Accessed: 2009-09-12

Sanchez, E. F. (2005). Estrategia de innovacion, Thomson, 112-319, Spain

Sarapovas, T. (2005). Electronic commerce models for increasing business effectiveness: summary of doctoral dissertation, Technologija, 1-130, Kaunas

Schmidt-Tiedemann, K. J. (1982). A new model of the innovation process. Research Management, 25, 18-21, ISSN 0034-5334

Tidd, J. (2006). A Review of Innovation Models, Discussion paper, 1-34, London

Tybout, J. (1991). Researching the trade-productivity link: new directions, World Bank Publications, 1-58, Washington

UNESCO (2010). UNESCO Science Report 2010: The Current Status of Science around the World, UNESCO Publishing, 5-19, France

Wheelwright, S. C. \& Clark, K. B. (1992). Revolutionizing Product Development: Quantum Leaps in Speed, Efficiency and Quality, The Free Press, 13-26, New York Zon, A. van; Sanders, M. \& Muysken, J. (1997). Modelling the link between skill biases in technical change and wage divergence through labour market extensions of Krugman's North-South model, In: Technology and the Future of European Employment, Petit, P. \& Soete, L. (Ed.), Edward Elgar Publishing, ISBN 1-84064517-2, Cheltenham 